\title{
Physostigmine-induced reversal of EEG and behavioral effects of $\Delta^{9}$-tetrahydrocannabinol
}

\author{
BYRON C. JONES, PAUL F. CONSROE, and FAREN AKINS \\ Department of Pharmacology and Toxicology and Department of Psychology \\ University of Arizona, Tucson, Arizona 85721
}

\begin{abstract}
The effects of $\Delta^{9}$-THC) in combination with physostigmine (PHYSO) on the electroencephalogram (EEG) and behavior were measured in adult unrestrained rabbits. The increase in mean cortical electrogenesis (voltage output) of the EEG induced by $\Delta^{9}$-THC was clearly reversed by PHYSO. Hippocampal theta rhythm disrupted by $\Delta^{9}$-THC was restored by PHYSO. Physostigmine also antagonized $\Delta^{9}$-THC-induced alteration of postural and activity behaviors. Except for very brief periods of retching, no behavioral indications of toxicity were observed.
\end{abstract}

Several investigators have suggested that the behavioral effects of $\Delta^{9}$-tetrahydrocannabinol ( $\Delta^{9}$.THC), the major psychoactive component of marihuana, may be one manifestation of its activity at central cholinergic pathways, especially in the limbic system. More specifically, Miller and Drew (1974) believe that $\Delta^{9}$-THC has anticholinergic (atropine-like) activity and that this anticholinergic activity is apparent especially in the hippocampus.

Alternatively, $\Delta^{9}$-THC did not block the cholinomimetic effects of tremorine in mice (Sofia, Kubena, and Barry, 1974) or physostigmine in rabbits (Consroe, 1973). Moreover, $\Delta^{9}$-THC has been shown to augment the cholinomimetic toxicity of physostigmine in rats (Rosenblatt, Janowsky, Davis, and El-Yousef, 1974). In humans, Freemon, Rosenblatt, and El-Yousef (1975) demonstrated that physostigmine may enhance the late effects of $\Delta^{9}$-THC, viz, lethargy and somnolence.

The present experiment was designed in order to investigate quantified EEG and behavioral changes in the presence of $\Delta^{9}$.THC, physostigmine, and their combination.

\section{METHODS}

\section{Subjects}

The subjects in the present experiment were nine New Zealand albino rabbits weighing between 3.0 and $4.5 \mathrm{~kg}$. All subjects were housed individually in a room main tained at $25^{\circ} \mathrm{C}$ and under a $12 \mathrm{~h}$ light-dark cycle. All subjects had surgically implanted chronic recording electrodes; the implantation procedure is described elsewhere (Consroe, Jones, and Chin, 1975). The loci of the recording electrodes were motor cortex, parietal (limbic) cortex, and dorsal hippocampus.

This investigation was supported by NIMH Research Grant MH23414. The $\Delta^{9}-$ THC was provided through the courtesy of Dr. Monique C. Braude of the FDA-NIMH Psychotomimetic Agents Advisory Committee. The authors thank Ms. Marilyn Bingham and Ms. Delores Robedeau for their technical assistance. We also thank Dr. Joseph E. Lyones for his editorial comments and sponsorship.

\section{Apparatus}

Unrestrained rabbits were tested in a chamber measuring $82 \mathrm{~cm}$ square $\times 70 \mathrm{~cm}$ high. A one-way view side window permitted behavioral observation, and shielded cable connected the subject's recording electrodes to a Grass Model 7B recorder.

\section{Drugs}

$\Delta^{9}$-T'etrahydrocannabinol $\left(\Delta^{9}-\right.$ THC) was prepared using a $10 \%$ polysorbate (Tween) 80 -saline solution as a vehicle. Physostigmine salicylate (PHYSO) was dissolved in $.85 \%$ saline. All drug dosages were calculated as the active base; drugs and vehicles were injected via the marginal ear vein and were administered in the volume of $.1 \mathrm{ml} / \mathrm{kg}$ body weight. The dose of $\Delta^{9}$-THC employed in the present study was $.5 \mathrm{mg} / \mathrm{kg}$ and was chosen on the basis of dose-response data (Consroe et al., 1975) that indicated that this dose produces characteristic EEG patterns without signs of behavioral toxicity, e.g., ataxia. Similarly, the dose of PHYSO $(.05 \mathrm{mg} / \mathrm{kg})$ was chosen for its consistent EEG changes and corresponding lack of toxicity, viz, fasciculations, drooling, etc. Drugs were given not more than once a week to any one animal.

EEG

Cortical EEGs were recorded from various bipolar leads and subsequently assessed qualitatively. In all animals, the electrical activity occurring between the left motor and right limbic cortical leads was integrated using the Grass Model 7P10B integrator system. The data reported here are mean frequency of integrator resets where each reset represents 70 microvolts. Additionally, hippocampal EEG tracings were assessed qualitatively for frequency and amplitude patterns.

\section{Behavior}

Postural and activity behaviors as described previously by Consroe et al. (1975) were measured.

\section{Procedure and Testing Sequence}

The subjects were allowed to recover from surgery for 10 days and then adapted to the testing apparatus/regimen as described previously (Consroe et al., 1975). The design of the present experiments permitted simultaneous recording of behavior and EEG for eight 4-min time samples spanning $54 \mathrm{~min}$, i.e., 0-4, 5-9, $10-14,20-24,30-34,35-39,40-44$, and 50-54 min. The treatment sequence was counterbalanced to control for sequence effects and consisted of: (1) Tween 80-saline (Tween 80-saline at time 0 followed $30 \mathrm{~min}$ later by saline). (2) THC-saline ( $\Delta^{9}$-THC at time 0 followed $30 \mathrm{~min}$ later by saline). (3) Saline-PHYSO (saline at time 0 followed $30 \mathrm{~min}$ later by PHYSO). (4) THC-physostigmine ( $\Delta^{9}$-THC at time 0 followed 30 min later 
Table 1

Mean Frequency of Integrator Resets Observed for Cortical EEG and Mean Durations (in Seconds) for Sprawling and Activity Behaviors

\begin{tabular}{|c|c|c|c|c|c|c|c|c|}
\hline & \multicolumn{8}{|c|}{ Treatment Sequence } \\
\hline & $\underset{(0-24 \mathrm{~min})}{\text { Tween }} \rightarrow$ & $\rightarrow \underset{(30-54 \mathrm{~min})}{\text { Saline }}$ & $\begin{array}{c}\Delta^{9}-\mathrm{THC} \\
(0-24 \mathrm{~min})\end{array}$ & $\rightarrow \underset{(30-54 \mathrm{~min})}{\text { Saline }}$ & $\begin{array}{l}\text { Tween } \\
(0-24 \mathrm{~min})\end{array}$ & $\rightarrow \underset{(30-54 \mathrm{~min})}{\text { PHYSO }}$ & $\begin{array}{c}\Delta^{9}-\mathrm{THC} \\
(0-24 \mathrm{~min})\end{array}$ & $\rightarrow \quad \begin{array}{c}\text { PHYSO } \\
(30-54 \mathrm{~min})\end{array}$ \\
\hline \multicolumn{9}{|c|}{ Mean Frequencies } \\
\hline $\begin{array}{l}\text { Integrator } \\
\text { Resets }\end{array}$ & $\begin{array}{l}73.77^{1} \\
\pm 4.37\end{array}$ & $\begin{array}{l}99.00^{2} \\
\pm 6.71\end{array}$ & $\begin{array}{l}134.22^{1} \\
\pm 15.24\end{array}$ & $\begin{array}{l}171.22^{4} \\
\pm 16.85\end{array}$ & $\begin{array}{l}66.78 \\
\pm 8.64\end{array}$ & $\begin{array}{l}54.89^{2} \\
\pm 5.98\end{array}$ & $\begin{array}{l}130.78^{3} \\
\pm 17.58\end{array}$ & $\begin{array}{l}59.67^{3,4} \\
\pm 7.11\end{array}$ \\
\hline \multicolumn{9}{|c|}{ Mean Durations (Sec) } \\
\hline Sprawl & $0^{1}$ & 0 & $\begin{array}{l}48.00^{1,2} \\
\pm 19.28\end{array}$ & $\begin{array}{l}122.56^{2,4} \\
\pm 32.47\end{array}$ & 0 & 0 & $\begin{aligned} & 76.44^{3} \\
\pm & 26.94\end{aligned}$ & $\begin{array}{l}28.67^{3,4} \\
\pm 10.33\end{array}$ \\
\hline Activity & $\begin{array}{l}29.56^{1} \\
\pm 8.89\end{array}$ & $\begin{array}{l}10.11^{2} \\
\pm 2.51\end{array}$ & $\begin{aligned} & 1.67^{1} \\
\pm & 1.10\end{aligned}$ & $\begin{array}{c}.22^{3} \\
\pm .14\end{array}$ & $\begin{array}{l}16.56 \\
\pm 4.51\end{array}$ & $\begin{array}{l}28.67^{2} \\
\pm 4.84\end{array}$ & $\begin{array}{r}9.67 \\
\pm 3.84\end{array}$ & $\begin{array}{l}19.11^{3} \\
\pm 3.90\end{array}$ \\
\hline
\end{tabular}

Note-Each mean ( $\pm S E$ ) is the average of the values obtained from nine rabbits observed for four 4-min time samples, i.e., $0-4,5-9,10-14$, and 20-24 min for Tween or $\triangle^{9}-T H C ; 30-34,35-39,40-44$, and 50-54 min for saline or PHYSO. Matching superscripts, e.g., $1-1,2-2$, etc., indicate reliable contrasts $(p<.05)$.

by PHYSO). Within each treatment period, drugs were given in the order indicated above. Earlier research in our laboratory (Consroe et al., 1975) revealed that the EEG and behavioral manifestations of $.5 \mathrm{mg} / \mathrm{kg} \Delta^{9}$-THC peaked at $30 \mathrm{~min}$ and persisted fully until at least $1 \mathrm{~h}$ after administration. Therefore, PHYSO, a drug which is a rapidly acting CNS and behavioral stimulant was administered during the peak of $\Delta^{9}$-THC activity.

\section{Data Analysis}

Analy ses of variance for two within-subjects variables were employed (Winer, 1971); each subject served as its own control. The Newman-Keuls multiple comparisons methods was used to evaluate differences between means. In order to facilitate data presentation, data were lumped into two segments, i.e., Time Samples 0-4 to 20-25 min (Treatment 1) and Samples 30-34 to 50-54 min (Treatment 2).

\section{RESULTS}

Table 1 presents the data. The integrated cortical activity showed a reliable amplitude increase after $\Delta^{9}$-THC treatment $(\mathrm{p}<.05)$. Additionally, PHYSO reliably reversed the $\Delta^{9}$-THC-induced increase in cortical EEG amplitude $(\mathrm{p}<.05)$. As expected, $\Delta^{9}$-THC disrupted the sinusoidal hippocampal theta rhythm. As with the cortical EEG, PHYSO reversed the $\Delta^{9}$-THC-induced change in the hippocampal trace, i.e., restored theta.

Behaviorally, $\Delta^{9}$ THC appeared to sedate the subject. Posturally, $\Delta^{9}$-THC tended to decrease the amount of standing, however the large variance in this behavior prevented even the large changes in the mean durations from being statistically reliable.

In contrast, the mean duration of sprawling (defined as the subject's head on the floor of the cage and limbs splayed laterally) occurred only following administration of $\Delta^{9}$-THC ( $\left.p<.05\right)$. As with the EEG, PHYSO reliably reduced the $\Delta^{9}$.THC induced sprawling $(\mathrm{p}>.05)$. The sprawling observed in the PHYSO condition following $\Delta^{9}$-THC pretreatment was observed exclusively during the first 4 min following PHYSO administration.

Activity behaviors, grooming, locomotion, rearing and exploration showed similar changes throughout the experiment, and their composite is presented in Table 1 . $\Delta^{9}$-THC depressed $(p<.05)$, whereas PHYSO increased the mean duration of activity $(\mathrm{p}<.05)$. The intrasession trend toward PHYSO reversing the $\Delta^{9}$-THC-induced depression of activity approached significance $(p<.10)$, and the intersession PHYSO-induced reversal of the $\Delta^{9}$-THC depressed activity was reliable $(\mathrm{p}<.05)$.

Additionally, three of the rabbits evinced brief bouts of retching without vomiting.

\section{DISCUSSION}

The results of this experiment show unequivocally that at the present dose levels, the sedative effects of $\Delta^{9}$-THC on EEG and behavior can be reversed by physostigmine. Further, with the exception of the brief periods of retching, we observed no unique interaction effects of the combination of the two drugs.

While our results may be considered as supportive of Miller's and Drew's (1974) proposal that $\Delta^{9}$-THC has anticholinergic properties, our results may have been due to nonspecific stimulant properties of physostigmine rather than direct antagonism. Indeed, physostigmine has been shown to reverse physiological depression induced by a variety of agents not considered to have specific anticholinergic effects. For example, physostigmine has been shown to reverse the depressant effects of haloperidol, chlorpromazine (Bernards, 1973; Consroe \& White, 1972), pentobarbital, pheneglycodol, and meprobamate (White \& Boyajy, 1959). In humans, coma resulting from tricyclic antidepressant poisoning has been reversed successfully with physostigmine (Slovis, Ott, Teitelbaum, \& Lipscomb, 1971).

Recently, physostigmine has been applied in treating humans self- or experimentally dosed with marihuana (El-Yousef, Janowsky, Davis, and Rosenblatt, 1973) or $\Delta^{9}-$ THC (Freemon et al., 1975). In both cases, physostigmine reversed the $\Delta^{9}$-THC-induced tachycardia and conjunctival injection, while in the former case, precipitating quasipathological depression and in the latter case producing lethargy and drowsiness.

In conclusion, $\Delta^{9}$-THC administration produces EEG and behavioral changes similar to the anticholinergics, atropine and scopolamine (Miller \& Drew, 1974). Further, these changes can be reversed by physostigmine. However, in light of the results of Consroe (1973) and Sofia et al. (1974), who failed to demonstrate reversal of cholinomimetic activity by treatment 
"Iith $د^{9}$-THC, it is difficult to ascribe specifically anticholinergic properties to $\Delta^{9}$-THC.

\section{REFERENCES}

Bernards, W. Reversal of phenothiazine-induced coma with physostigmine. Anesthesia and Analgesia, 1973, 52, 938-941.

Consroe, P. F. Effect of $\Delta^{9}$-tetrahydrocannabinol on a cholinergic-induced activation of the electroencephalogram in the rabbit. Research Communications in Chemical Pathology and Pharmacology, 1973, 5, 705-712.

Consroe, P. F., Jones, B. C., \& Chin, L. $\Delta{ }^{9}$-t'etrahydrocannabinol, EEG, and behavior: The importance of adaptation to the testing milieu. Pharmacology, Biochemistry, and Behavior, in press, 1975.

Consroe, P. F., \& White, R. P. Effects of haloperidol and chlorpromazine on central adrenergic and cholinergic mechanisms in rabbits. Archives of International Pharmacody namics and Therapeutics, 1972, 198, 67-75.

El-Yousef, M. K. Janowsky, D. S., Davis, J. M., \& Rosenblatt, J. E. Induction of severe depression by physostigmine in marijuana intoxicated individuals. British Journal of Addiction, 1973, 68, 321-325.
Freemon, F. R., Rosenblatt, J. E., \& El-Yousef, M. K. Interaction of phy sostig ine and delta-9-tetrahydrocannabinol in man. Clinical Pharmacology and Therapeutics, 1975, 17, 121-126.

Miller, L. L., \& Drew, W. G. Cannabis: Review of behavioral effects in animals. Psychological Bulletin, 1974, 81, 401-417. Rosenblatt, J. E., Janowsky, D. S., Davis, J. M., \& El-Y ousef, M. $K$. The augmentation of physostigmine toxicity in the rat by $\Delta$ - te trahydrocannabinol. Research Communications in Chemical Pathology and Pharmacology, 1972, 3, 479-482.

Slovis, T. L., Ott, J. E., Teitelbaum, D. T., \& Lipscomb, W. Physostigmine therapy in acute tricyclic antidepressant poisoning. Clinical Toxicology, 1971, 451-459.

Sofia R. D. Kubena, R. K., \& Barry, H. Inactivity of $\Delta$ ' -tétrahydrocannabinol in antidepressant screening tests. Psy chopharmacologia, 1973, 31, 121-130.

White, R. P., \& Boy ajy, L. D. Comparison of physostigmine and amphetamine in antagonizing the EEG effects of CNS depressants. Proceedings of the Society for Experimental Biology and Medicine, 1959, 102, 479-483.

winer, B. J. Statistical methods in experimental design. New York: McGraw-Hill, 1971.

(Received for publication April 24, 1975.) 